\title{
Propuesta de enseñanza de inglés para escuelas normales
}

\author{
Normal Schools English Learning Proposal \\ Proposta de ensino de inglês para escolas normais \\ Jorge Rebollo Sánchez \\ Escuela Normal de Atlacomulco, México \\ jorge.rebollo@escuelanormaldeatlacomulco.edu.mx \\ https://orcid.org/0000-0002-2669-5491
}

\section{Resumen}

En este artículo de investigación se presenta el proyecto de una plataforma interna de inglés por niveles, alojada en una suite interna de WordPress, como una estrategia remedial de tutoría especializada para nivelar a alumnos cuyo dominio del inglés es muy limitado en normales públicas, a sabiendas que la especialidad en inglés demanda un nivel B2 al cuarto año de carrera, meta poco alcanzable considerando la cantidad de horas asignadas de estudio y práctica del idioma.

Hoy, el estudiante mexicano normalista se ha de apropiar del inglés como lengua extranjera por medio de cursos curriculares establecidos en el plan de estudios 2018, dentro de un trayecto formativo de lengua adicional, con una inversión de seis horas semanales. Aun así, no se garantiza ni la calidad ni la eficiencia ni el adecuado y objetivo nivel del egresado frente a los retos, reales, de un mundo actual sin maquillaje. ¿Qué hacer? ¿Qué se propone como estrategia de enseñanza para asegurar el éxito del plan de estudios 1999? La respuesta operativa, diseñada y puesta en marcha, se presenta en esta investigación. Dicha propuesta se piloteó con dos generaciones de la Escuela Normal de Atlacomulco, Español, Historia e Inglés, en el uso de la Learning Management System (LMS) o plataforma de aprendizaje, desde su ingreso, permanencia y egreso, apoyados de recursos alternos de autoría propia, y de talleres alternos de práctica del inglés a contraturno. 


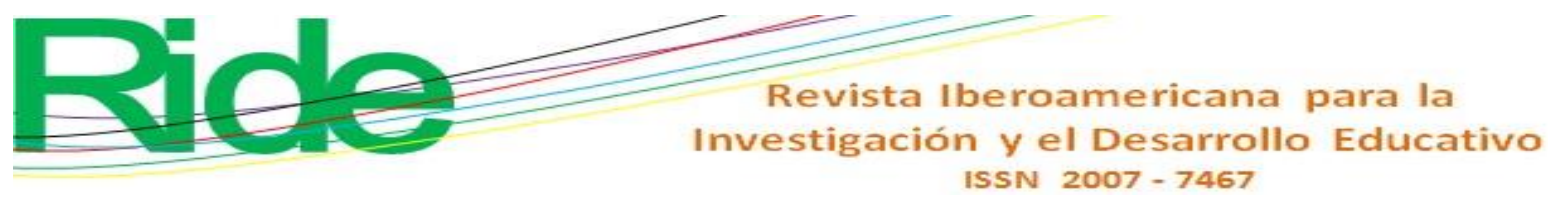

Palabras clave: enseñanza de idiomas, laboratorio de idiomas, reforma del programa educativo.

\section{Abstract}

Through the years of experience in public normal schools, with the 1999 study plan, the project of an internal Learning Management System of English by levels, hosted in an internal Wordpress suite, is introduced as a remedial strategy of specialized tutoring to level students whose English is very limited in public normal institutions, knowing that the specialty in English demands a B2 level in the fourth year of the degree, a goal that is not attainable considering the number of hours assigned to study and practice the language.

At present, the normalista Mexican student has to acquire English as a foreign language, through curricular courses established in the 2018 curriculum, within a formative path of additional language, with an investment of six weekly hours. Even so, neither the quality, nor the efficiency, nor the adequate and objective level of the graduate is guaranteed in face of the real challenges of a current world without makeup. What to do? What is it proposed as a teaching strategy to ensure the success of the 1999 curriculum? The operational response, designed and implemented, is introduced in this research, piloting two Escuela Normal de Atlacomulco generations in the use of the Learning Management System (LMS), since its admission, permanence and graduation, supported by alternative resources of my creation, and alternative English practice workshops in the afternoon shift.

Keywords: language teaching, language lab, educational program reform.

\section{Resumo}

Este artigo de pesquisa apresenta o projeto de uma plataforma interna de inglês por níveis, alojada em uma suíte interna do WordPress, como uma estratégia de tutoria especializada para nivelar estudantes cuja proficiência em inglês é muito limitada em padrões públicos, conscientemente que a especialidade em inglês exige um nível B2 no quarto ano de carreira, uma meta que não é alcançável considerando a quantidade de horas alocada para estudo e prática de idiomas.

Hoje, o estudante mexicano normalista deve se apropriar do inglês como língua estrangeira por meio de cursos curriculares estabelecidos no currículo de 2018, dentro de um curso 
adicional de treinamento de idiomas, com um investimento de seis horas por semana. Mesmo assim, nem a qualidade, nem a eficiência, nem o nível adequado e objetivo da pós-graduação são garantidos contra os desafios reais de um mundo atual sem maquiagem. O que fazer? O que é proposto como estratégia de ensino para garantir o sucesso do currículo de 1999? A resposta operacional, projetada e implementada, é apresentada nesta investigação. Esta proposta foi testada com duas gerações da Escola Normal de Atlacomulco, Espanhol, História e Inglês, no uso do Sistema de Gerenciamento de Aprendizagem (LMS) ou plataforma de aprendizado, desde a sua entrada, permanência e descarga, apoiada por recursos alternativos de autoria. próprio, e de oficinas alternativas de prática de inglês para contraturno.

Palavras-chave: ensino de idiomas, laboratório de idiomas, reforma de programas educacionais.

\section{Introducción}

Lograr que un alumno de escuela normal pública alcance un nivel B2 en inglés en 3.5 años de su carrera no es tarea fácil, máxime si pensamos en quienes llegan a la educación superior con una terrible precariedad lingüística. No se discuten los porqués en la presente investigación, sino se atiende a los medios.

Apegados al hecho de que el alfabetismo del siglo XXI no consiste en desarrollar la lectoescritura sino en dominar las tecnologías de la información y la comunicación (TIC) y lenguas adicionales, en términos estandarizados por el sistema educativo mexicano, el inglés se vuelve una necesidad social que se ha visto reflejada en lo académico, con las reformas y propuestas educativas. En la presente investigación se revisa el estatus de dos escuelas normales públicas del Estado de México en torno a la enseñanza de una lengua extranjera, inglés, así como en lo concerniente a la intervención áulica. Se revisa la propuesta de una cartera de opciones en torno a la enseñanza, a través de un proyecto sólido de tutoría especializada, piloteado en una plataforma electrónica gratuita diseñada e instalada en el Laboratorio de Idiomas de la Escuela Normal de Atlacomulco, en Intranet en Wordpress, incluyendo talleres de conversación, lectura y escritura, y aunado a cursos impartidos por medio de otros tres sistemas de gestión de aprendizaje (LMS, por sus siglas en inglés): 




Revista Iberoamericana para la Investigación y el Desarrollo Educativo ISSN $2007-7467$

Empower, New Interchange y Schoology. Se proyecta a futuro como un diseño de cursos de inglés por niveles alojado en una plataforma con licencia, también en la LMS Schoology, además de convertirla en aplicación para celulares en el alumnado normalista. A la fecha de marzo de 2019 el trabajo tiene un avance de $50 \%$.

Se enfatiza que el objeto de estudio de la presente investigación y actual proyecto surge como una alternativa de bajo costo para escuelas normales públicas debido a que resulta imposible mantener económicamente una plataforma con licencia que supera los 80 dólares por alumno por semestre. No existen trabajos previos de esta índole en el Estado de México, y de allí el atrevimiento de proponer esta alternativa viable, pertinente y accesible, remedial como recurso de nivelación para el aumento de uso y dominio del idioma inglés. Si bien se operan plataformas con licenciamiento en algunas instituciones, no hay tal comparativo con la propuesta interna empleando solamente software libre.

Se acota que la presente propuesta de investigación surgió antes que el nuevo modelo educativo del plan de estudios 2018 fuera instalado. La plataforma interna propuesta y puesta en marcha está más enfocada, por tanto, a los alumnos del plan de estudios 1999, que, a la fecha, no han egresado. Es decir, el modelo 2018 ya está en marcha, pero las instituciones que ya ofrecían el plan 1999 tuvieron que hacer que ambos planes coexistieran. El modelo 2018 cuenta con seis horas curriculares de aprendizaje del inglés como lengua extranjera. No así plan 1999, que ni siquiera en primer grado es contemplado como curso ni como taller. Del mismo modo, se debe mencionar que, en marzo de 2019, la Dirección General de Educación Superior para Profesionales de la Educación (DGESPE) invirtió una muy valiosa cantidad en la compra de una plataforma de licencia, efectiva y de calidad, nombrada Discovery, de la compañía Edusoft. Este proyecto surge en el año 2012, cuando tal inversión no era siquiera pensable.

Es pertinente y necesario enmarcar brevemente los antecedentes en el marco educativo y político de las acciones tomadas para subsanar y resolver la problemática del bajo nivel de inglés, de aprendizaje y de aprovechamiento en las aulas de educación básica, media superior y superior.

Desde 2016, y en el marco de la reforma educativa que inició con una fase piloto en 2011 y se consolidó en 2012, noté que en las escuelas normales de Ixtlahuaca y Atlacomulco los egresados no contaban con los conocimientos suficientes en el uso y dominio de la lengua inglesa como requisito curricular, además de las limitadas herramientas didácticas para 




Revista Iberoamericana para la Investigación y el Desarrollo Educativo ISSN 2007 - 7467

impartirlo. Esto dio pauta inmediata sobre la pertinencia de realizar una investigación de campo, así como de establecer una propuesta sólida sobre la habilitación de recursos para resolver la situación problemática que se enfrenta. Trazo los siguientes datos históricos para dar fe de que, si bien ya la intención iniciaba desde antaño, las propuestas no arrojaban los resultados esperados.

Ya desde el 15 de mayo de 2008, con la Alianza por la calidad de la educación (Secretaría de Educación Pública [SEP], 2008), se colocaba al inglés en una posición prioritaria o privilegiada dentro del currículo mexicano; el tan añorado sueño nacional de aspirar a una nación bilingüe no más allá del año 2025. Lejos de un sueño utópico, como manera de enfrentar el proceso de globalización dentro del cual estamos inmersos, en el documento citado se declara la formación integral de los alumnos para la vida y el trabajo, y de modo particular, la enseñanza del idioma inglés desde preescolar y la promoción de la interculturalidad (p. 22). Sin embargo, esto se declaraba como prioritario pese a que los medios no existían para subsanar tal necesidad.

Dicha Alianza era ya la continuación del Compromiso Social por las Calidad de la Educación (CSCE), signado en agosto de 2002 por el presidente Vicente Fox y Elba Esther Gordillo; y el Acuerdo Nacional para la Modernización de la Educación Básica (Anmeb), firmado en mayo de 1992 por el presidente Carlos Salinas de Gortari y la maestra Gordillo. Entre todo, ya se veía la meta clara: el diseño de la educación pública nacional. Recordando las metas trazadas en ese tiempo, se buscaba como centro del escenario a los alumnos mejor preparados y más aptos para insertarse plenamente en un mundo globalizado y en constante transformación, a través de la enseñanza del idioma inglés como una política de Estado. Se aspiraba a una cobertura universal de educación básica en México, con alta calidad, lo que aseguraba alumnos-ciudadanos más aptos y exitosos para salir al mundo. Esto a través de la formalidad de la enseñanza del inglés desde el preescolar, regulado por el Programa Nacional de Inglés para Educación Básica (PNIEB).

En México, desde la inclusión del PNIEB (2009-2013), dentro de los cursos (fases) de $3 .^{\circ}$ de preescolar y hasta $3 .^{\circ}$ de secundaria se proponía ya un proceso secuencial en aras de que en esta ocasión, de una vez por todas, como tantas veces lo hemos aseverado, el estudiante obtuviera los elementos necesarios para incursionar en un inglés intermedio en la educación media superior y superior, y, como en una educación primermundista, a dar por 
hecho el dominio del español y del inglés en la educación superior, preparado para incursionar en la práctica de una tercera lengua.

De 2014 a 2015 el PNIEB cambió su nombre al Fomento de los Procesos de Estudio de una Segunda Lengua: Inglés (FPESLI); y a partir de 2016 toma su nombre actual: Programa Nacional de Inglés (Proni). Con todo ello, sin reparar en nomenclaturas, la intención siempre ha sido positiva: posicionar a México en la adquisición de una segunda lengua o lengua extranjera, a saber, el inglés, ante los vertiginosos tiempos ya rebasados a que nos enfrentamos dentro de la vorágine de la globalización.

Todo el recorrido histórico anterior aterriza para las normales públicas de la siguiente manera. Si la enseñanza del inglés parte ahora de $3 .^{\circ}$ de educación preescolar y continúa en educación primaria y secundaria, y aún más, se asume que en educación media superior el alumno cuenta con cursos de inglés progresivo, es decir, no nuevamente los mismos temas del verbo to be, números, animales y colores, sino tiempos compuestos y temarios de inglés básico superior y bajo intermedio; si esto es así, en la fase piloto de 2011, en la reforma educativa a normales que arrancó en 2012 para educación preescolar, entre otras, se instruye que el inglés formará parte de la malla curricular de las licenciaturas de educación normales citadas, al menos, con una inversión de seis horas semanales, comenzando de un nivel A1 y culminando con un nivel B2, como se puede observar en la figura 1. 
Figura 1. Mapa curricular de las licenciatura en educación preescolar. Plan de estudios

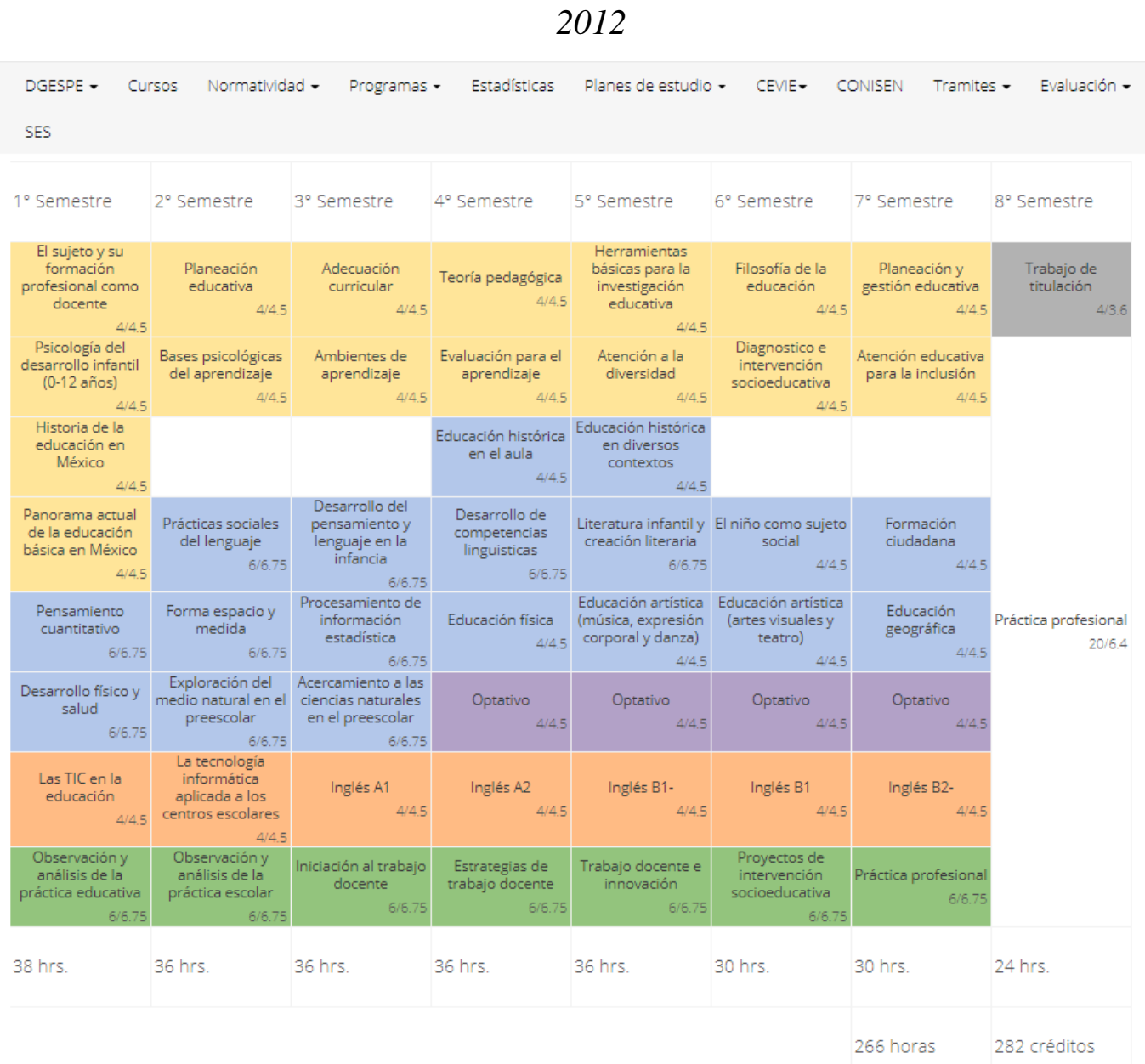

Fuente: SEP (2012)

El trayecto de aprendizaje de una segunda lengua se traza en un sentido tal que el inglés comienza a practicarse en $2 .^{\circ}$ grado y en $7 .^{\circ}$ semestre se espera que el alumno alcance el nivel intermedio o B2. En otras palabras, con cuatro horas semanales, cero refuerzo o estrategia complementaria, se pretende alcanzar el nivel A1 en $3 .^{\text {er }}$ semestre; A2 en $4 .^{\circ}$ semestre; B1- en 5..$^{\circ}$ semestre; B1 en $6 .^{\circ}$ semestre, y B2 en 7.. Así es, no por ciclo escolar o año lectivo, sino por semestre se pretende avanzar un nivel. Esto para los especialistas en el idioma, en la cuestión didáctico-pedagógica, es, si bien no un sinsentido, un reto casi imposible de lograr. Al menos con los recursos dispuestos, considerando el origen geográfico del alumnado, y los conocimientos previos precarios con que llegan a la educación superior.

Ya en el nuevo modelo educativo 2018 se traza la meta de lograr un nivel intermedio o B2 al culminar la carrera, tal como muestra la figura 2, por citar alguno, el mapa curricular de la Licenciatura en Español (plan 2018): 


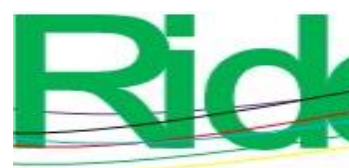

Revista Iberoamericana para la Investigación y el Desarrollo Educativo ISSN $2007-7467$

Figura 2. Mapa curricular del Plan de Estudios 2018, Licenciatura en Enseñanza y Aprendizaje en Educación Secundaria, Español



Fuente: SEP (2018)

Mientras que en el sector privado el alumno posee conocimientos de inglés en educación preescolar, y un nivel de inglés suficiente en educación media superior, ya sea que curse preparatoria bilingüe o incluso completamente en inglés; en normales públicas nos hemos aún de conformar con una carga horaria de escasas cuatro horas semanales en el plan 1999, a las cuales hay que añadirles, en muchas ocasiones, docentes sin perfil, periodos sin sesión debido a prácticas profesionales, días de asueto, etc., que en lugar de provocar avance representan un verdadero reto a superar: lograr que en menos tiempo el alumno alcance un nivel adecuado de inglés, equivalente a un nivel intermedio dentro del sistema de medición mexicano: Certificación Nacional de Nivel de Idioma (Cenni). Sin lugar a dudas es una carrera contra el tiempo. 


\section{Método}

Dentro de este contexto nacional es que nace esta propuesta pedagógica, desde el umbral del diseño curricular. En el nuevo modelo educativo 2018 ya se contempla el inglés como asignatura curricular con los siguientes cambios a favor: se instruye impartir seis horas semanales en lugar de cuatro. Y se instruye como asignatura curricular desde $1 .{ }^{\mathrm{er}}$ semestre y hasta $6 .^{\circ}$ semestre. ¿Qué se puede observar? Que, si bien se postula como contenido curricular, dándole su real importancia desde el inicio de la carrera, es detenido en $3 .{ }^{\text {er }}$ grado, lo cual no resuelve el problema, sino solo lo adelanta. ¡Comienza antes, pero termina en la misma cantidad de semestres! Aumenta la carga horaria de cuatro a seis horas semanales, pero siguen siendo solo tres años de cursar la asignatura. Y considerando la sumatoria de horas, grosso modo estaríamos hablando de 100 horas efectivas de contacto con el idioma por semestre. Esto, en razón de que interfieren días inhábiles, periodos de evaluación, y estancias de prácticas profesionales en instituciones de educación básica.

La problemática del tiempo no es la meta en sí, sino la temporalidad y los medios tan limitados para lograrlo. De modo particular en lo que se refiere al tiempo efectivo de exposición del alumno al lenguaje.

De modo remedial en las escuelas normales de Ixtlahuaca en 2014 y Atlacomulco de 2016 a la fecha se instaló un sistema de tutoriales de inglés por niveles con base en ligas de software libre (LIENI), y que, llevado paralelamente al inglés curricular, habría de encaminar al alumnado a obtener un nivel B2 al iniciar el $4 .^{\circ}$ grado de licenciatura, meta probada en esta investigación. Esa es la problemática concreta, y el modo de abordarla con la perspectiva didáctica que presento en la presente investigación.

A diferencia de plataformas registradas, entre las cuales podemos mencionar a Discovery (de Edusoft), Speex (de Centro Cultural Multimedia de Lenguas [CCML]), Educational Time (de Ediciones Culturales Internacionales), la nuestra se basa en software libre por ser dirigida a grupos de escasos recursos. Por consecuencia, su rango de funciones es muy limitado; por ejemplo, un docente ha de estar presente para aclarar dudas y registrar resultados, pues no se tiene un sistema automatizado.

La Escuela Normal de Ixtlahuaca, citando un ejemplo, que ofrece la Licenciatura en Educación Preescolar, adoptó en el ciclo escolar 2013-2014 una plataforma o suite interna de inglés por niveles, como complemento formativo a los cursos curriculares, partiendo de un diagnóstico institucional (a alumnos y docentes), cuyo resultado fue asignar un curso 


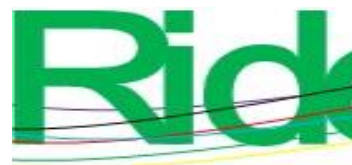

Revista Iberoamericana para la

Investigación y el Desarrollo Educativo

ISSN $2007-7467$

adecuado a sus saberes y necesidades, además de alojar varios recursos didácticos en una LMS de Schoology. En conjunto, se incluyó la habilitación para estudiantes de cursos curriculares, talleres de inglés para docentes, cursos de inglés para docentes en servicio (externos) y habilitación de docentes bajo el esquema PNIEB en su momento. Esto además de un Laboratorio de Inglés con recursos de software libre, por declararse como una institución de bajos recursos, y cuyo diseño estuvo a mi cargo, primer intento de la plataforma de inglés por niveles que vendría a coronar este proyecto en la Escuela Normal de Atlacomulco, ya con alumnos especializados en lengua extranjera (inglés). Desafortunadamente, el proyecto fue detenido al ciclo escolar siguiente por políticas internas (se puede consultar el proyecto respectivo). Luego retomado con un enfoque de Tutoría Especializada en Inglés, a partir del cual se obtuvieron resultados muy favorables en la generación 2011-2015, y finalmente detenido por el robo del equipo de cómputo donde se operaba el programa mencionado.

El ejemplo citado busca aludir al hecho de que la cantidad de horas efectivas asignadas refleja - se guste mirar desde este enfoque o no- la poca importancia que se le había dado a la enseñanza del idioma, bajo el argumento de que las normales no son especialistas en inglés sino en docencia; que somos instituciones formadoras de docentes, no de egresados en lenguas. En este sentido, aludir al caso fáctico, a partir del cual, con un incremento de horas efectivas frente al idioma inglés, el alumnado mostró un notable avance en comparación a las brechas académicas de antes de instalarse el proyecto de autoría propia. Aunque la presente investigación se acota a la Escuela Normal de Atlacomulco. La figura 3 ilustra la cantidad de horas (6) semanales que la nueva currícula 2012 y 2018 establece para escuelas normales: 


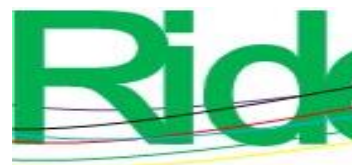

\section{Revista Iberoamericana para la Investigación y el Desarrollo Educativo ISSN $2007-7467$}

Figura 3. Mapa curricular del Plan de Estudios 2018, Licenciatura en Enseñanza y Aprendizaje en Educación Secundaria, Inglés
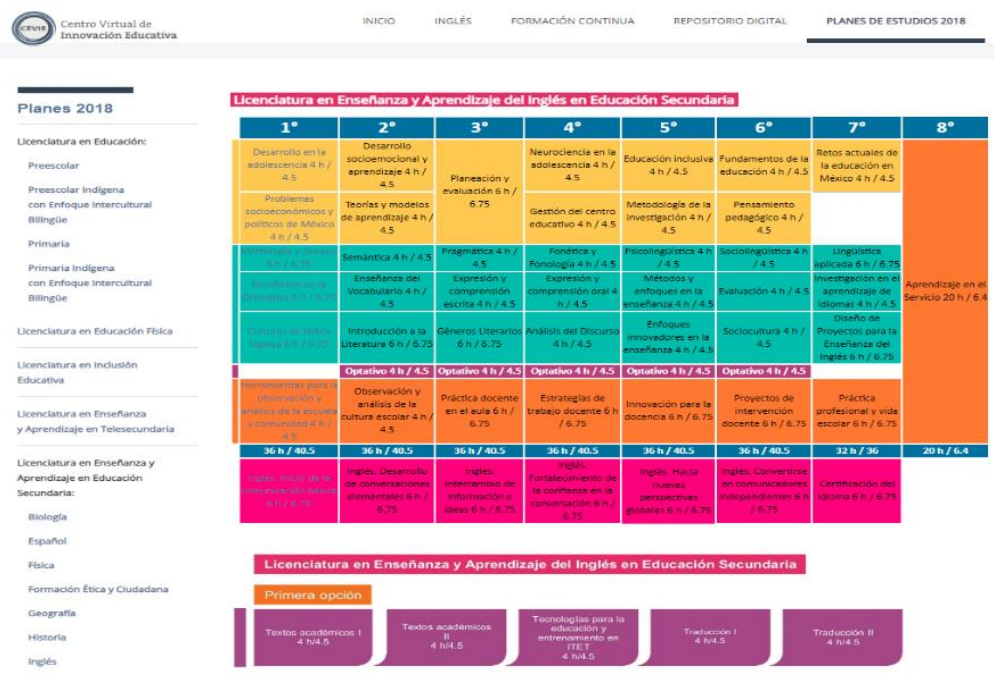

Fuente: SEP (2018)

Lo que la presente investigación demuestra en la Escuela Normal de Atlacomulco, después de 9 años de trabajo de campo con alumnos de licenciatura, con énfasis en aquellos cuya especialidad es el inglés, es que seis horas para un alumno que llega con escasos referentes de educación básica y media superior en torno al idioma inglés es muy poco tiempo de contacto con el lenguaje. ¿Qué estrategia se implementó? Bien. Como inicio, después de un curso propedéutico de 50 horas (casi nada comparado, por ejemplo. con el sistema educativo de las universidades técnico-pedagógicas, que superan las 400 horas), para los candidatos a cursar la especialidad en inglés se les aplica un examen de diagnóstico al inicio del curso, y uno de ubicación al final del mismo, cincos horas semanales, 50 horas de duración. Para aquellos candidatos a cursar Historia y Español, solo se les aplica lamentablemente un examen de ubicación previo al inicio de su licenciatura, para saber en qué nivel iniciará su historia académica en torno al inglés como asignatura, en una plataforma por niveles, instalada en la institución, como ya se ha comentado suficiente, en modalidades presencial, semipresencial en plataforma de aprendizaje, y de trabajo autónomo (en self-study mode, con New Interchange, y con una plataforma de Empower como guía, según el curso, el nivel y la carrera).

Ya iniciados los cursos de especialidad del ciclo escolar en general, además de atender los cursos curriculares de seis horas por semana, para las tres licenciaturas impartidas en la institución, Español, Historia e Inglés, en contraturno, se ha operado con una duración de 68 


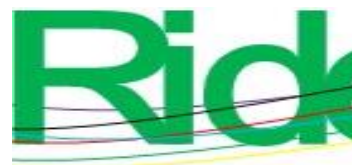

Revista Iberoamericana para la
Investigación y el Desarrollo Educativo
ISSN $2007-7467$

horas semestrales de 2008 a 2014, y 80 horas semanales hasta el presente, traducidas en cuatro horas semanales de sesiones de inglés a través del denominado Centro Regional de Lenguas (CRELe), un plan alternativo de reforzamiento para el alumnado normalista que consiste en una serie de cursos que en algún momento (en su creación en 2008) fue pensado como course preparation para certificaciones en KET, PET y FCE, pero que, más tarde, al notar que no era la meta requerida en el mercado educativo, se trazó un rediseño y se tomó entonces un nuevo enfoque hacia el perfeccionamiento del inglés en un sistema de inglés por niveles, de A2, B1 y B2.

Con un aproximado de 100 horas/semestre en turno matutino en enseñanza del inglés por niveles, más 80 horas/semestre en modalidad CRELe vespertino, es como se impulsa desde el método de práctica efectiva de la lengua en modalidad presencial, con asistencia de un docente. Pero esto es solo un momento, quizá para este instante de lectura, advertido como presente en otras escuelas normales públicas, y por ende sin mayor novedad. Pero esperen. Es solo el inicio.

En algún momento, de igual modo, se pensó en una estrategia remedial externa, outsourcing, donde el alumno, en caso de no alcanzar la banda 10 en $1 .^{\text {er }}$ grado, la banda 11 en $2 .^{\circ}$ grado y la banda 12 en $3 .^{\circ}$ grado, se vería en la necesidad académica de invertir en un curso remedial externo, ya fuese en un instituto privado o en instituciones como Edayo, e incluso en becas parciales como el Programa Nacional de Inglés Para Todo México, que comenzó en un boom y ha terminado en nada. Parafraseando, programas caducos, sin seguimiento, cursos sin una meta específica en sus planteamientos curriculares, gastos sin fondo, y aún, alumnos en rezago. De modo ilustrativo, la figura 4 refleja el plan estratégico para desarrollar los cursos de inglés en la Escuela Normal de Atlacomulco en su inicio: 
Figura 4. Propuesta curricular para la impartición de inglés en Escuela Normal de Atlacomulco. Junio de 2016. Proyecto institucional de inglés 2016.
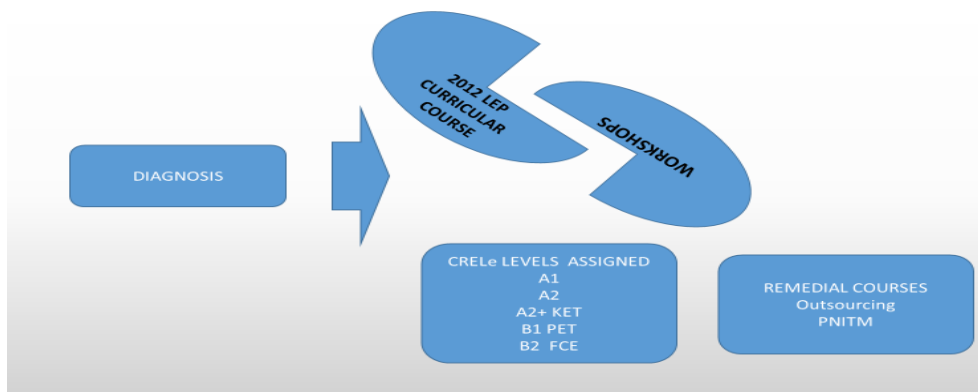

Fuente: Elaboración propia

He aquí donde surge la propuesta de autoría propia. En lugar de hacer que nuestro alumnado vaya a probar alternativas, invirtiendo dinero y esfuerzo, oferta tras oferta sin un éxito asegurado, y sin que el tiempo se detenga, diseñé una propuesta de una serie de ejercicios de refuerzo, montados en una plataforma interna, en una plantilla de Wordpress (la escuela no contaba con recursos para pagar una licencia en suites como Schoology o Edmodo, u otras); una serie, como decíamos, de ejercicios por nivel en tres habilidades (listening, reading, writing), ya que practicar speaking es complicado en sitios de Internet sin costo. No obstante, también se incluyen ejercicios de gramática y vocabulario, con la finalidad de revisar, practicar, reforzar y fortalecer lo que el alumno revisa en sus cursos matutinos y vespertinos. Qué mejor opción que ejercitarse en práctica de habilidades lingüísticas afines al diseño curricular completo, y no en sistemas de inglés en instituciones cuyo enfoque no es exactamente el impartido en la escuela normal, y que es un enfoque sociocultural, comunicativo, e integrativo de las cuatro habilidades.

Se lleva un acompañamiento tutorial por parte de dos docentes del área de idiomas, quienes resuelven dudas, dan consejos acerca de la habilidad, tema, o lo requerido para llevar a cabo la actividad. No se pudo aspirar a más tiempo, pues la carga horaria, los días festivos, y los periodos de práctica en escuelas secundarias reducen notablemente la posibilidad de expandir este proyecto a algo aún más ambicioso, incluyendo talleres de reading, writing y speaking. Enseguida se pueden observar algunas muestras de cómo está conformada la LMS interna en la Escuela Normal de Atlacomulco, en un laboratorio con 25 equipos conectados en red. 


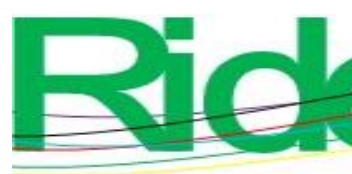

Revista Iberoamericana para la Investigación y el Desarrollo Educativo ISSN $2007-7467$

Figura 5. Imágenes de pantalla de la suite interna de autoría propia, en Wordpress

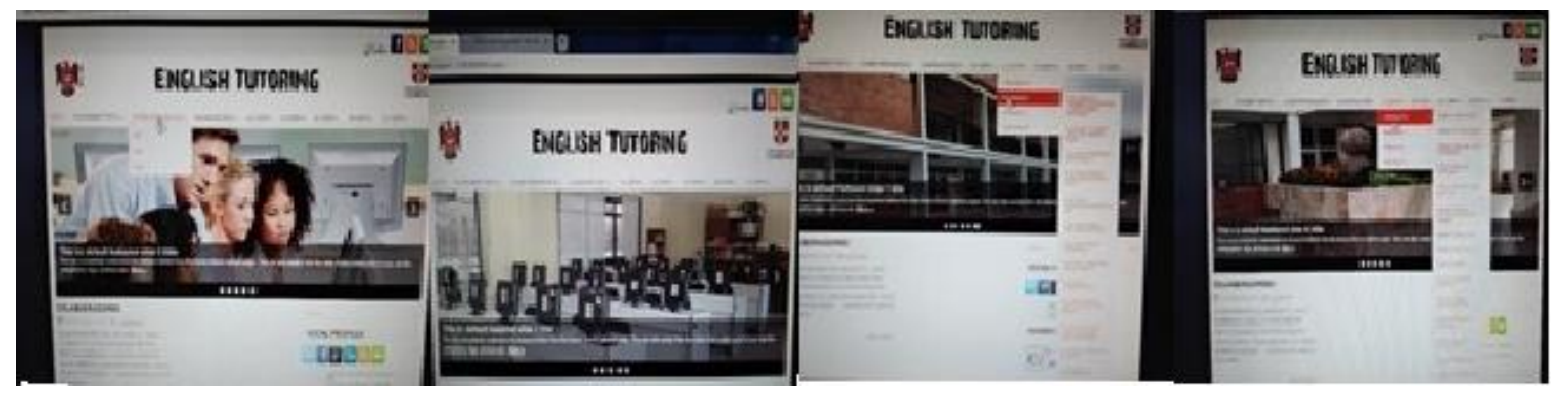

Fuente: Elaboración propia

Se observa la página principal de bienvenida, y una muestra desplegada de cuatro variantes de exámenes de ubicación y diagnóstico, además de mock tests para las certificaciones en KET, PET, FCE, así como las diversas pestañas de servicio, catalogadas por nivel, y una vez seleccionado el nivel por habilidad. Dentro de la habilidad, se despliega una vasta cantidad de ejercicios de práctica. Cada uno se acompaña de imágenes atractivas motivantes, instrucciones, el link de acceso que abrirá el ejercicio en una ventana emergente, a fin de que la página principal siempre permanezca abierta, cuando el usuario decida regresar al portal principal; finalmente, se compone de una imagen motivadora de ejercicio culminado, la cual invita al usuario a continuar. Es la LMS propuesta en la presente investigación.

En cuanto al número de horas efectivas de contacto con el idioma inglés, tenemos entonces seis horas curriculares, más cuatro vespertinas por semana, más un refuerzo sobre habilidades y necesidades específicas de modo semanal mediante 10 y 15 horas de práctica en el Centro de Autoacceso (Laboratorio de Idiomas), según la carrera cursada, todo lo cual ha dado como resultado que una cantidad muy notable de alumnos de las tres especialidades aumenten gradual pero notablemente su nivel de inglés, para lograr alcanzar un nivel intermedio, B2 acorde al Marco Común Europeo de Referencia (MCER), o banda 12 en la escala Cenni. Este nivel los convierte en alumnos idóneos para graduarse como docentes con nivel aceptable dentro de rangos internacionales, para convertirse en docentes de inglés, como paso inmediato a su formación inicial, y listos apenas para incursionar en ulteriores certificaciones y cursos superiores. Estarían cruzando apenas el umbral de la formación inicial, hacia la formación permanente o continua. En la figura 6 se muestran los alcances esperados, en 2016, con base en la propuesta establecida: 
Figura 6. Niveles esperados en Escuela Normal de Atlacomulco, por licenciatura y por grado. Junio de 2016

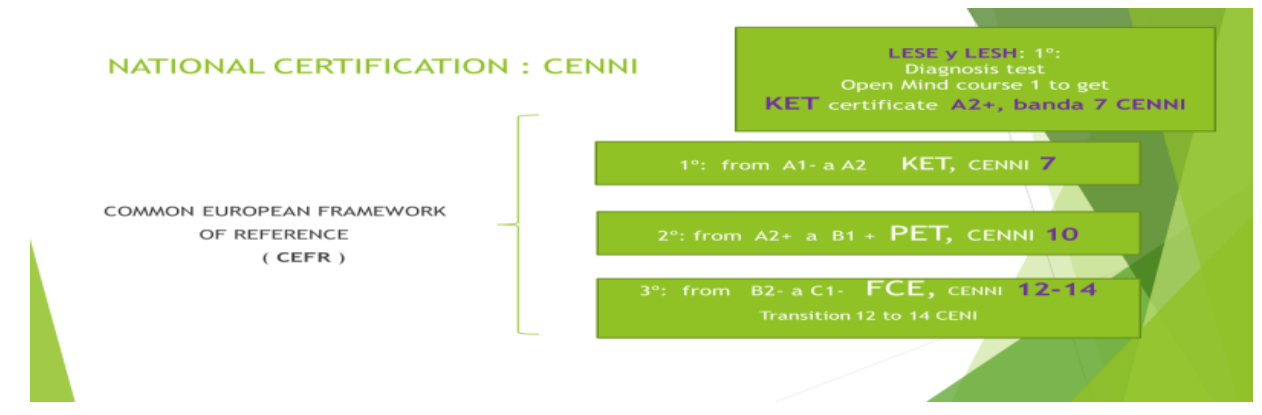

Fuente: Elaboración propia

La organización del sistema normalista en Atlacomulco, a mi cargo, ha sido en los últimos años como se muestra en la tabla 1:

Tabla 1. Sistema de inglés por niveles, instalado en Escuela Normal de Atlacomulco, por licenciatura, por grado. Proyecto institucional de inglés. Junio de 2016

\begin{tabular}{|c|c|c|c|c|c|c|c|}
\hline 1 & $\begin{array}{c}\text { CURSO } \\
\text { AGO } \\
2016 \\
- \\
\text { ENE } \\
2017\end{array}$ & $\begin{array}{c}\text { NOMBRE } \\
\text { DEL } \\
\text { PROFESOR } \\
2016-2017\end{array}$ & $\begin{array}{c}\text { NOMBRE } \\
\text { DEL } \\
\text { PROFESOR } \\
2017- \\
\text { ENERO } \\
2018\end{array}$ & $\begin{array}{c}\text { CURSO } \\
\text { AGO } \\
2017- \\
\text { ENERO } \\
2018\end{array}$ & $\begin{array}{l}\text { CURSO } \\
\text { ENE - } \\
\text { JUL } \\
2018\end{array}$ & $\begin{array}{c}\text { PROFESOR } \\
2018 \mathrm{~A}\end{array}$ & $\begin{array}{c}\text { TEXTO } \\
\text { CURSO } \\
\text { SECUENCIA } \\
\text { Agosto } \\
2018- \\
\text { ENERO } \\
2019\end{array}$ \\
\hline 2 & OM 1 & $\begin{array}{l}\text { Profra. } \\
\text { Patricia } \\
\text { Navarrete } \\
\text { Mejía }\end{array}$ & $\begin{array}{l}\text { Cinthya } \\
\text { Barranco } \\
\text { Huitrón }\end{array}$ & $\begin{array}{c}\text { Empower } \\
\text { A2 } \\
1-6\end{array}$ & $\begin{array}{c}\text { Empower } \\
\text { A2 } \\
7-12\end{array}$ & $\begin{array}{c}\text { Ydalmi Cruz } \\
\text { Bello }\end{array}$ & $\begin{array}{c}\text { Empower } \\
\text { B1 } \\
1-6\end{array}$ \\
\hline 3 & OM 1 & $\begin{array}{l}\text { Mtra Yedid } \\
\text { Monroy } \\
\text { Segundo }\end{array}$ & $\begin{array}{c}\text { Ydalmi } \\
\text { Cruz Bello }\end{array}$ & $\begin{array}{l}\text { Open } \\
\text { Mind } 2 \\
7-12\end{array}$ & $\begin{array}{c}\text { Empower } \\
\text { B1 } \\
1-6\end{array}$ & $\begin{array}{l}\text { Yadira Corral } \\
\text { Garduño }\end{array}$ & $\begin{array}{c}\text { Empower } \\
\text { B1 } \\
7-12\end{array}$ \\
\hline 4 & OM 2 & $\begin{array}{c}\text { Mtro. } \\
\text { Florencio } \\
\text { González } \\
\text { Cruz }\end{array}$ & $\begin{array}{l}\text { Teresa } \\
\text { Posadas } \\
\text { Cárdenas }\end{array}$ & $\begin{array}{l}\text { Open } \\
\text { Mind } 3 \\
7-12\end{array}$ & $\begin{array}{c}\text { Empower } \\
\text { B1+ } \\
1-6 \\
\text { (+ } 2 \text { Ss } \\
\text { de MM1) }\end{array}$ & $\begin{array}{l}\text { Cinthya } \\
\text { Barranco } \\
\text { Huitrón }\end{array}$ & $\begin{array}{c}\text { Empower } \\
\text { B1+ } \\
7-12\end{array}$ \\
\hline 5 & OM 3 & $\begin{array}{l}\text { Profra. } \\
\text { Angélica } \\
\text { Cárdenas } \\
\text { Mendoza }\end{array}$ & $\begin{array}{l}\text { Mtro. Jorge } \\
\text { Rebollo S. }\end{array}$ & $\begin{array}{l}\text { Master } \\
\text { Mind } 1 \\
7-12\end{array}$ & --- & $\begin{array}{c}\text { DESAPARECE } \\
\text { (fusión a } \\
\text { Empower } \\
\text { B1+) }\end{array}$ & ---- \\
\hline 6 & MM 1 & $\begin{array}{l}\text { Profra. } \\
\text { Yadira } \\
\text { García } \\
\text { Corral }\end{array}$ & $\begin{array}{l}\text { Mtro. } \\
\text { Rodrigo } \\
\text { Zaldivar } \\
\text { Pérez }\end{array}$ & $\begin{array}{l}\text { Master } \\
\text { Mind 2 } \\
7-12\end{array}$ & $\begin{array}{c}\text { Empower } \\
\text { B2 } \\
1-6\end{array}$ & $\begin{array}{c}\text { Adriana } \\
\text { Monroy } \\
\text { Rodríguez }\end{array}$ & $\begin{array}{c}\text { Empower } \\
\text { B2 } \\
7-12\end{array}$ \\
\hline 7 & MM2 & $\begin{array}{l}\text { Mtro. Jorge } \\
\text { Rebollo } \\
\text { Sánchez }\end{array}$ & $\begin{array}{c}\text { Mtro. } \\
\text { Sergio } \\
\text { Hernández } \\
\text { Hernández }\end{array}$ & $\begin{array}{l}\text { On } \\
\text { Screen } \\
\text { B2 } \\
1-4\end{array}$ & $\begin{array}{c}\text { On } \\
\text { Screen } \\
\text { B2 } \\
5-8\end{array}$ & Jorge Rebollo & $\begin{array}{c}\text { On Screen } \\
\text { B2 + } \\
1-6\end{array}$ \\
\hline
\end{tabular}

Fuente: Elaboración propia 
En cuanto a la sección de CRELe (cursos a contraturno del Centro Regional de Lenguas) se muestra a continuación, en la tabla 2:

Tabla 2. Sistema de inglés por niveles en CRELe, modalidad a contraturno, instalado en la Escuela Normal de Atlacomulco. Proyecto Inglés CRELe. Junio de 2017

\begin{tabular}{|c|c|c|c|c|c|c|c|}
\hline \multicolumn{8}{|c|}{$\begin{array}{c}\text { AGOSTO } 2017 \text { ENERO } 2018 \\
\text { DOCENTES CURSO SEMANAL LUNES - MARTES 16:00 - 18:00 }\end{array}$} \\
\hline & & $\begin{array}{c}\text { NOMBRE } \\
\text { DEL } \\
\text { PROFESOR } \\
\text { Ago } 2016 \text { - } \\
\text { Ene } 2017 \\
\end{array}$ & $\begin{array}{c}\text { NOMBRE } \\
\text { DEL } \\
\text { PROFESOR } \\
2017\end{array}$ & CURSO & $\begin{array}{l}\text { SUBSTITUCIONE } \\
\text { S } \\
2017-2018\end{array}$ & $\begin{array}{l}\text { LUN - } \\
\text { MART } \\
\text { 4-6 pm }\end{array}$ & $\begin{array}{l}\text { JAN } 2018 \\
\text { Teachers }\end{array}$ \\
\hline 1 & FCE & $\begin{array}{l}\text { KENIA } \\
\text { MORALES } \\
\text { VELÁZQUEZ }\end{array}$ & $\begin{array}{l}\text { KELY } \\
\text { RAMIREZ } \\
\text { ESCOBAR }\end{array}$ & $\begin{array}{l}\text { PREPARACIO } \\
\text { N } \\
\text { FCE LESI 3o }\end{array}$ & $\begin{array}{c}\text { ANGÉLICA } \\
\text { CÁRDENAS } \\
\text { MENDOZA } \\
\text { (ENA) }\end{array}$ & $\begin{array}{c}\text { On Screen } \\
\text { B1 + } \\
\text { Units 1-4 }\end{array}$ & $\begin{array}{c}\text { SERGIO } \\
\text { HERNANDE } \\
\text { Z H }\end{array}$ \\
\hline 2 & PET & $\begin{array}{l}\text { ISAIAS } \\
\text { FUENTES } \\
\text { NAVARRO }\end{array}$ & $\begin{array}{l}\text { OCTAVIO } \\
\text { ROSALES } \\
\text { ROSALES }\end{array}$ & $\begin{array}{l}\text { PREPARACIO } \\
\text { N } \\
\text { PET LESI } 2^{\circ}\end{array}$ & & $\begin{array}{c}\text { Empower } \\
\text { B1 } \\
\text { Units 1- } 6 \\
\text { PEER } \\
\text { TEACHIN } \\
\text { G } \\
\end{array}$ & $\begin{array}{c}\text { ADRIANA } \\
\text { MONROY } \\
\text { RODRIGUEZ }\end{array}$ \\
\hline 3 & KET & $\begin{array}{l}\text { KELY } \\
\text { RAMIREZ } \\
\text { ESCOBAR }\end{array}$ & $\begin{array}{c}\text { LESLIE } \\
\text { MARLEN } \\
\text { GONZALEZ } \\
\text { NAVA }\end{array}$ & $\begin{array}{l}\text { PREPARACIO } \\
\text { N } \\
\text { KET LESI } 1 \stackrel{0}{ }\end{array}$ & $\begin{array}{l}\text { TERESA DE } \\
\text { JESUS POSADAS } \\
\text { CÁRDENAS } \\
\text { (ENA) } \\
\text { SERGIO } \\
\text { HERNANDEZ H }\end{array}$ & $\begin{array}{c}\text { Empower } \\
\text { A } 2 \\
\text { units 7-12 } \\
\text { PEER } \\
\text { TEACHIN } \\
\text { G } \\
\end{array}$ & $\begin{array}{c}\text { PATRICIA } \\
\text { NAVARRETE } \\
\text { MEJIA } \\
\text { CINTHYA } \\
\text { BARRANCO } \\
\text { HUITRON }\end{array}$ \\
\hline 4 & & $\begin{array}{l}\text { VICTOR } \\
\text { HUGO } \\
\text { MANUEL } \\
\text { ALCÁNTARA }\end{array}$ & $\begin{array}{l}\text { ITANIA } \\
\text { RAMIREZ } \\
\text { ESCOBAR }\end{array}$ & $\begin{array}{c}\text { INGLÉS } \\
\text { EMPOWER A2 } \\
\text { LESH } \\
\text { Units 1-6 } \\
\end{array}$ & $\begin{array}{c}\text { CINTHYA } \\
\text { BARRANCO } \\
\text { HUITRÓN } \\
\text { (ENA) }\end{array}$ & $\begin{array}{l}\text { Empower } \\
\text { A } 2 \\
\text { units 7-12 }\end{array}$ & $\begin{array}{l}\text { YDALMI } \\
\text { CRUZ } \\
\text { BELLO }\end{array}$ \\
\hline 5 & & $\begin{array}{l}\text { HEIDI } \\
\text { GERALDINE } \\
\text { VEGA } \\
\text { VELASQUEZ }\end{array}$ & $\begin{array}{l}\text { ISAIAS } \\
\text { FUENTES } \\
\text { NAVARRO }\end{array}$ & $\begin{array}{c}\text { INGLÉS } \\
\text { EMPOWER A2 } \\
\text { LESE } \\
\text { Units } 1 \text {-6 }\end{array}$ & & $\begin{array}{c}\text { Empower } \\
\text { A2 } \\
\text { Units } 7-12\end{array}$ & $\begin{array}{l}\text { YDALMI } \\
\text { CRUZ } \\
\text { BELLO }\end{array}$ \\
\hline 6 & $\begin{array}{c}\text { Ope } \\
\text { n } \\
\text { Mind } \\
1\end{array}$ & $\begin{array}{l}\text { PATRICIA } \\
\text { NAVARRETE } \\
\text { MEJIA }\end{array}$ & $\begin{array}{c}\text { ZEUDY DALÍ } \\
\text { SERVÍN } \\
\text { JASSO }\end{array}$ & $\begin{array}{c}\text { INGLÉS } \\
\text { TRAVELLER } \\
\text { B1 } \\
\text { Units 1-4 }\end{array}$ & & $\begin{array}{c}\text { Traveller } \\
\text { B1 } \\
\text { units 5-8 }\end{array}$ & $\begin{array}{l}\text { RODRIGO } \\
\text { ZALDIVAR } \\
\text { PÉREZ }\end{array}$ \\
\hline 7 & $\begin{array}{c}\text { Ope } \\
n \\
\text { Mind } \\
1\end{array}$ & $\begin{array}{l}\text { HEIDI } \\
\text { GERALDINE } \\
\text { VEGA } \\
\text { VELASQUEZ }\end{array}$ & $\begin{array}{l}\text { ARMANDO } \\
\text { GUADARRAM } \\
\text { A TORRES }\end{array}$ & $\begin{array}{c}\text { INGLÉS } \\
\text { TRAVELLER } \\
\text { B1 } \\
\text { Units 1 - } 4 \\
\end{array}$ & & $\begin{array}{c}\text { Traveller } \\
\text { B1 } \\
\text { Units 5-8 }\end{array}$ & $\begin{array}{c}\text { ANGÉLICA } \\
\text { CÁRDENAS } \\
\text { MENDOZA } \\
\text { LISA MARISA } \\
\text { DE LA CRUZ } \\
\text { BECERRIL }\end{array}$ \\
\hline
\end{tabular}

Fuente: Elaboración propia

Los estudiantes son medidos bajo instrumentos objetivos al fin de cada ciclo escolar, y el desempeño de muestras de población estudiantil se despliegan enseguida. Como titular del área de idiomas, piloteo método, texto y plataforma por generación, y monitoreo en el 

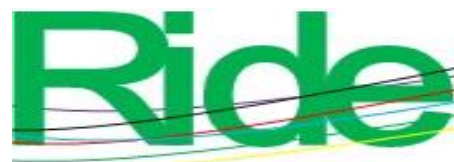

Revista Iberoamericana para la

Investigación y el Desarrollo Educativo

ISSN $2007-7467$

mismo sentido. Al final de primer grado no es objetivo hablar de meta en sentido estricto, por ser solo objetivos alcanzado de modo gradual, procesal, mas no terminal.

\section{Resultados}

La muestra de resultados equivale a una generación de cuatro años bajo la propuesta descrita, desde su ingreso hasta el 4. ${ }^{\circ}$ grado de su carrera. La Escuela Normal de Atlacomulco se encuentra en fase de implementación de una plataforma de aprendizaje con software gratuito, alojada en Wordpress, y en espera de personal técnico para ser alojada en una suite de licenciamiento, para su puesta en práctica no solo en Intranet, como hasta la fecha, sino en Internet, donde el usuario, desde la comodidad de su hogar, pueda practicar las habilidades básicas del idioma, y nivelar de este modo el nivel de inglés que se le demanda para el grado de carrera que esté cursando del mismo modo, y con la mismas cualidades de la piloteada en la Escuela Normal de Ixtlahuaca, con la diferencia diametral que Ixtlahuaca no contaba con más de un docente con preparación y certificación en inglés, mientras que Atlacomulco ofrece la Licenciatura en Educación Secundaria con Especialidad en Inglés, y como se supone, ciertamente cuenta con una planta docente certificada en el idioma, pese a que aún opera con el plan de estudios 1999.

Toda la comunidad estudiantil cursando la especialidad en inglés es medida al fin de cada ciclo escolar bajo un instrumento externo de medición, Aptis, administrado en la institución por medio de The British Council; son examinados en las cuatro habilidades, y se obtienen dos resultados: uno conforme al MCER, y otro con valor CENNi, si el caso es revalidar y obtener el certificado nacional de idioma. A continuación se muestra, en las tablas 3 y 4; Figuras 10 y 11, el progreso o evolución del alumnado muestra en su aprendizaje del inglés. 

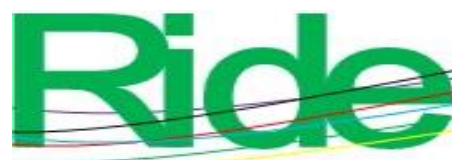

Revista Iberoamericana para la Investigación y el Desarrollo Educativo ISSN $2007-7467$

Figura 7. Muestra de evolución de inglés por niveles mediante un online placement test (OPT). Informe final Inglés. Julio de 2017

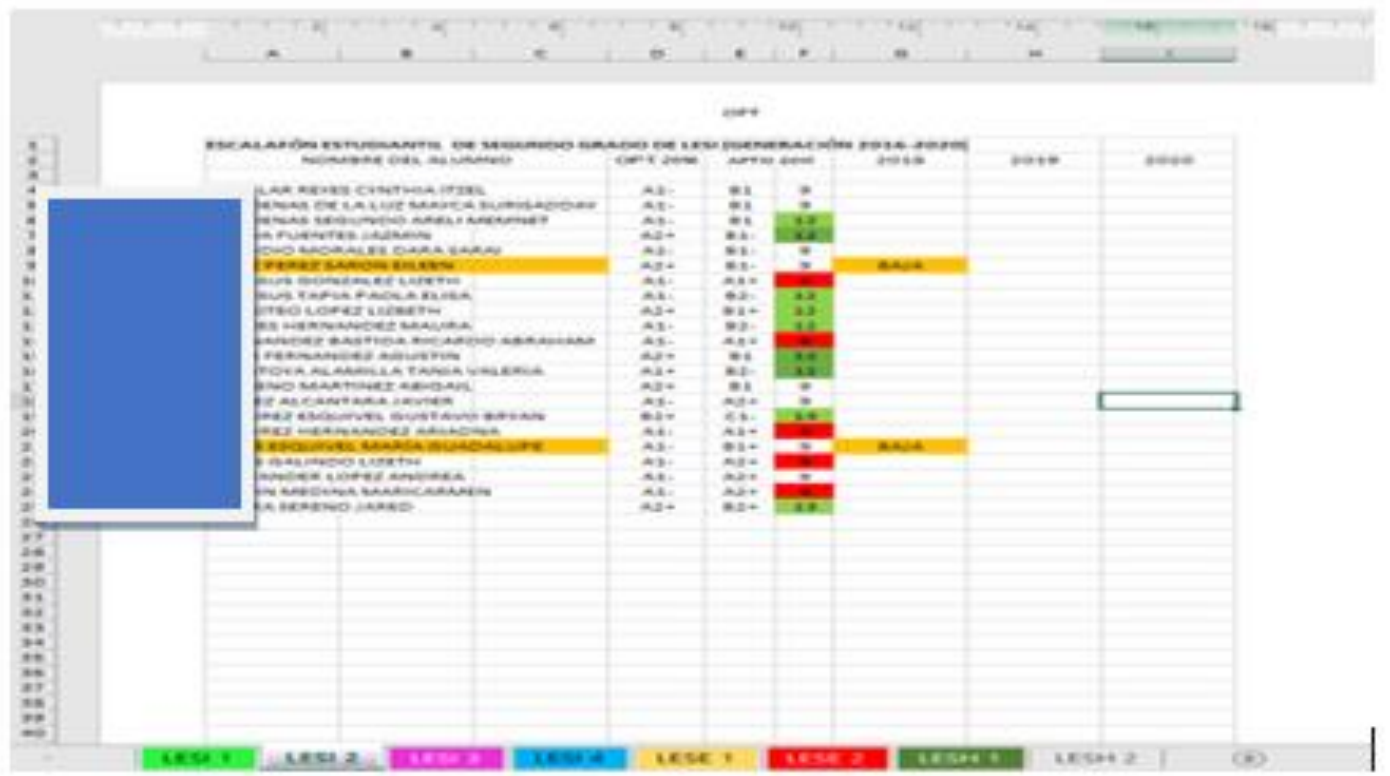

Fuente: Elaboración propia

Alumnos que están en el $4 .^{\circ}$ grado de Licenciatura en Inglés, así es como se denota su evolución en el idioma: 
Figura 8. Muestra de evolución de inglés por niveles mediante Aptis. Informe final Inglés.

Junio de 2019

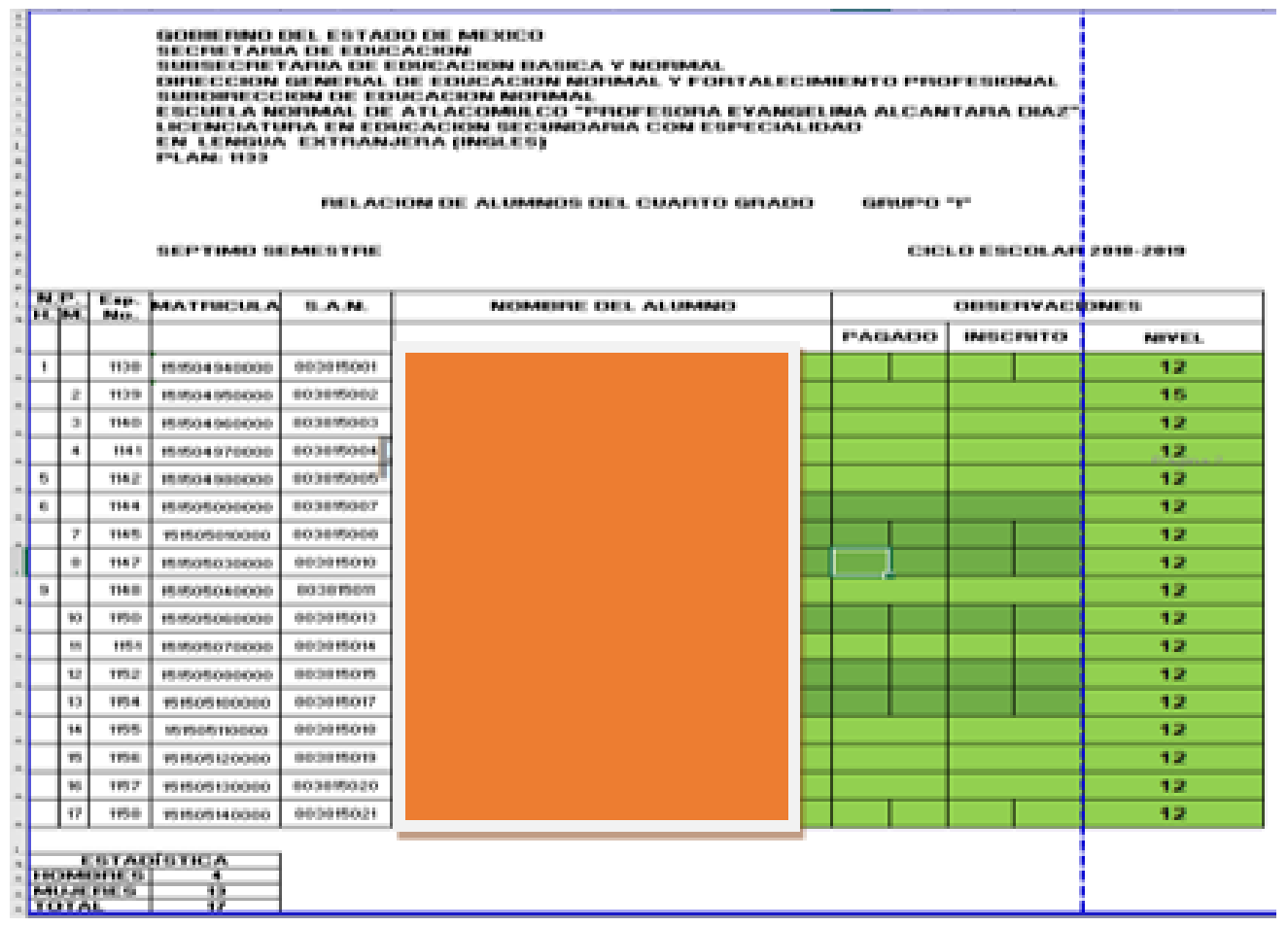

Fuente: Elaboración propia

Figura 9. Muestra de evolución de inglés por niveles, en $4 .^{\circ}$ grado de Licenciatura en Educación Secundaria con Especialidad en Lengua Extranjera (Inglés, LESI), mediante Diagnosis Test of English (DTES). Informe final Inglés. Julio de 2018

\begin{tabular}{|c|c|c|c|c|c|c|}
\hline \multicolumn{7}{|c|}{ STUDIANTIL DE CUARTO GRADO DE LESI (GENERACIÓN 2014-2018) } \\
\hline \multicolumn{2}{|c|}{ IEL ALUMNO } & \multirow{2}{*}{ 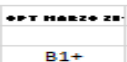 } & \multicolumn{2}{|c|}{ OPT JUL1o ze1 OPT 2016} & \multirow{2}{*}{ DTES 2017} & \multirow{2}{*}{ BAWDA } \\
\hline ZLA & & & $81+$ & $82+$ & & \\
\hline \multicolumn{2}{|c|}{ MARIA JOSE } & A1- & A1+ & A1+ & B2- & 11 \\
\hline \multicolumn{2}{|c|}{ ANGELASHAREL } & A1+ & A1+ & A1+ & B2 2 & 12 \\
\hline \multicolumn{2}{|c|}{ MAYOLO } & A1+ & A1+ & A1+ & B2- & 12 \\
\hline \multicolumn{2}{|c|}{ DANIELA } & A.2+ & B1+ & $\mathrm{B} 2+$ & $\mathrm{B} 2$ & 12 \\
\hline \multicolumn{2}{|l|}{ ARIANA } & A1- & A1+ & A1+ & $\mathrm{B} 2$ & 12 \\
\hline \multicolumn{2}{|c|}{ ZNANDO } & A.2+ & A.2+ & C1 & B2+ & 13 \\
\hline \multicolumn{2}{|c|}{ LARIA YESENIA } & A.1- & A1+ & A.2+ & B2- & 12 \\
\hline \multicolumn{2}{|c|}{ Z MANUEL } & A1+ & A2+ & B2+ & $\mathrm{B} 2$ & 12 \\
\hline \multicolumn{2}{|c|}{ AR MIGUEL ANGEL } & A1- & A1- & A1- & B1+ & 10 \\
\hline \multicolumn{2}{|c|}{ ABIMAEL } & A1+ & A1+ & $\mathrm{A} 2+$ & B2- & 11 \\
\hline ITZEL & & A1- & A1 & A.2+ & B2- & 12 \\
\hline \multirow{2}{*}{\multicolumn{2}{|c|}{$\begin{array}{l}Z \text { DENIS AVIGAIL } \\
Z \text { DAPE }\end{array}$}} & A.1+ & A2+ & $A 2+$ & $\mathrm{B} 2$ & 12 \\
\hline & & A1- & A1+ & A1+ & B2- & 11 \\
\hline HHAM & & $\mathrm{A}_{1}+$ & A2+ & A1+ & B2 & 12 \\
\hline SES & & A1+ & A1- & B1+ & B2- & 12 \\
\hline RAT & & A.1 + & A.1- & B2+ & B2 & 11 \\
\hline LIZBETH & & A1- & A1 & A1+ & $\mathrm{B} 1+$ & 12 \\
\hline ANA & & A1- & A1+ & $\mathrm{A}_{2+}+$ & B2- & 12 \\
\hline
\end{tabular}

Fuente: Elaboración propia

Se muestran referentes desde nuevos ingresos, en las especialidades de Historia y Español, así como el proceso evolutivo de quienes van escalando en su formación, cuyo plan de estudios se especifica en las cejas del archivo: 
Tabla 3. Muestra de evolución de inglés por niveles mediante un OPT, durante un ciclo escolar a un grupo de 1. ${ }^{\circ}$ de Licenciatura en Educación Secundaria con Especialidad en Lengua Extranjera (Inglés, LESI), con cursos de inglés matutino versus contraturno.

Informe final Inglés. Julio de 2018

\begin{tabular}{|c|c|c|c|c|c|}
\hline N.P & NOMBRE DEL ALUMNO & $\begin{array}{c}\text { CALFICACIÓN } \\
\text { CRELE }\end{array}$ & $\begin{array}{l}\text { CALIFICACIÓN } \\
\text { NIVEL DE INGLÉS }\end{array}$ & $\begin{array}{l}\text { CALIFIIACAÓN } \\
\text { CRELE }\end{array}$ & $\begin{array}{l}\text { CALIFICACIÓN } \\
\text { NIVEL DE INGLÉS }\end{array}$ \\
\hline 1 & $\begin{array}{l}\text { ALCANTARA ARRIAGA JOSE } \\
\text { FRANCISCO }\end{array}$ & 8.1 (FCE) & 9.3 & & \\
\hline 2 & $\begin{array}{l}\text { ALCANTARA SEGUNDO } \\
\text { GUADALUPE }\end{array}$ & 7.1 & 8.3 & & \\
\hline 3 & BARDOMIANO BERNARDO ANAHY & & 9.7 & & \\
\hline 4 & $\begin{array}{l}\text { CALDERON SANCHEZ VALERIA } \\
\text { NICOLE }\end{array}$ & 8.5 & 9.3 & & \\
\hline 5 & CARDENAS CARDENAS JOSE MARIA & 8.4 (PET) & 10.0 & & \\
\hline 6 & CARMONA HUITRON ESTHER & 8.4 & 9.7 & & \\
\hline 7 & DE JESUS MARTINEZ MIRIAM & 7.3 & 9.0 & & \\
\hline 8 & DE JESUS SIMON ITZEL LIZETH & 7.1 & 9.0 & & \\
\hline 9 & ESPINOZA LOPEZ VIRIDIANA & 8.6 & 10.0 & & \\
\hline 10 & FIDENCIO MARTINEZ MARIANA & 8.1 & 9.7 & & \\
\hline 11 & GARCIA LEON BRENDA ITZEL & & 9.7 & & \\
\hline 12 & $\begin{array}{l}\text { GONZALEZ DOMINGUEZ MAR } \\
\text { AYLIN }\end{array}$ & 8 & 9.0 & & \\
\hline 13 & $\begin{array}{l}\text { GUZMAN GONZALEZ FRANCISCO } \\
\text { JAVIER }\end{array}$ & & 10.0 & & \\
\hline 14 & HERNANDEZ ZALDIVAR MARI CRUZ & 8.7 & 8.3 & & \\
\hline 15 & HIPOLITO REYES WENDY LUZ & 7.3 & 8.3 & & \\
\hline 16 & MENDOZA DOMINGO ALONDRA & 6.7 & 10.0 & & \\
\hline 17 & MONTIEL GONZALEZ ANA KAREN & 8.1 & 9.3 & & \\
\hline 18 & NAVA ALCANTARA MIRIAM & 9.5 (PET) & 9.7 & & \\
\hline 19 & NAVARRETE GARCIA CLAUDIA & 10 (FCE) & 9.7 & & \\
\hline 20 & NIETO GUADARRAMA ESMERALDA & 8.6 & 9.3 & & \\
\hline 21 & PADILLA PEREZ MIRIAM & 8 & 9.7 & & \\
\hline 22 & PLATA PLATA ALAN ANTONIO & 7.0 (PET) & 9.0 & & \\
\hline 23 & SANCHEZ GAMA ABRIL LINETTE & & 8.3 & & \\
\hline 24 & SANCHEZ LOPEZ JESSICA MICHELLE & 8.7 & 10.0 & & \\
\hline 25 & SEGUNDO GIL MONSERRAT & 8.0 (PET) & 9.3 & & \\
\hline 26 & ZALDIVAR DE LA ROSA VIRIDIANA & 8.3 & 10.0 & & \\
\hline
\end{tabular}

Fuente: Elaboración propia

Hay que hacer notar que la lectura de los hallazgos se ha de hacer cuidadosamente, pues la asistencia ha sido un factor importante en el progreso o retraso del proceso de aprendizaje del alumno. No todo resultado obedece a la capacidad académica y de aprendizaje del alumno, como se aprecia en el seguimiento al siguiente grupo (ver tabla 4). 

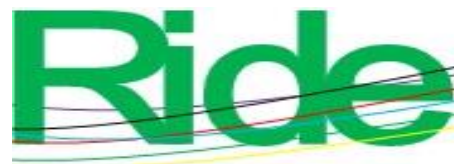

Revista lberoamericana para la Investigación y el Desarrollo Educativo ISSN $2007-7467$

Tabla 4. Muestra de evolución de inglés por niveles mediante un OPT, en un grupo de Licenciatura en Educación Secundaria con Especialidad en Inglés durante dos ciclos escolares, con cursos de inglés matutino versus contraturno. Informe final Inglés. Julio de 2018

\begin{tabular}{cl} 
N.P & \multicolumn{1}{c}{ NOMBRE DEL ALUMNO } \\
1 & AGUILAR REYES CYNTHIA ITZEL \\
2 & CARDENAS DE LA LUZ MAYCA SURISADDAY \\
3 & CARDENAS SEGUNDO ARELI MEMNET \\
4 & CERDA FUENTES JAZMIN \\
5 & CLAUDIO MORALES DARA SARAI \\
6 & CRUZ PEREZ SARON EILEEN \\
7 & DE JESUS GONZALEZ LIZETH \\
8 & DE JESUS TAPIA PAOLA ELISA \\
9 & DOROTEO LOPEZ LIZBETH \\
10 & FLORES HERNANDEZ MAURA \\
11 & HERNANDEZ BASTIDA RICARDO ABRAHAM \\
12 & ISLAS FERNANDEZ AGUSTIN \\
13 & MONTOYA ALAMILLA TANIA VALERIA \\
14 & MORENO MARTINEZ ABIGAIL \\
15 & NUÑEZ ALCANTARA JAVIER \\
16 & RAMIREZ ESQUIVEL GUSTAVO BRYAN \\
17 & RAMIREZ HERNANDEZ ARIADNA \\
18 & REYES GALINDO LIZETH \\
19 & SANTANDER LOPEZ ANDREA \\
20 & SERVIN MEDINA MARICARMEN \\
21 & VIEYRA SERENO JARED
\end{tabular}

\begin{tabular}{|c|c|c|}
\hline \multicolumn{3}{|c|}{ 2016-2017 } \\
\hline CALIFICACIÓN CRELE & $\begin{array}{l}\text { CALLFICACIÓN NIVEL DE } \\
\text { INGLÉS }\end{array}$ & CALLFI \\
\hline 7.35 & 7.3 & \\
\hline 7.85 & 8.0 & \\
\hline 8.7 & 9.0 & \\
\hline 8.2 & 10.0 & \\
\hline 8 & 8.0 & \\
\hline 6.4 & 9.0 & B \\
\hline 8.75 & 5.7 & \\
\hline 8.15 & 8.7 & \\
\hline 8.6 & 8.3 & \\
\hline 7 & 9.0 & \\
\hline \multirow[t]{2}{*}{6.3} & 6.0 & 1 \\
\hline & 7.3 & \\
\hline 8.85 & 8.7 & \\
\hline 8.3 & 8.3 & \\
\hline \multirow[t]{2}{*}{7.65} & 6.3 & \\
\hline & 9.0 & \\
\hline 7.9 & 7.0 & \\
\hline 6.4 & 7.3 & \\
\hline 8.5 & 8.3 & \\
\hline 6.35 & 6.0 & \\
\hline 8.55 & 9.7 & \\
\hline
\end{tabular}

2017-2018

CALIFICACIÓN NIVEL DE

6.5 NGLES

7.7 8.0

8.8

8.7

10.0

7.7

8.3

BAJA

6.5

BAJA

6.1

5

7.6

N.P

7.8

N.P

6

6

8

6.7

9.0

8.3

9.7

6.3

7.3

7.3

9.0

6.7

9.3

6.7

7.7

9.0

7.3

9.0

Fuente: Elaboración propia

Se muestra a continuación el concentrado de las especialidades en Historia y Español desde el momento de su ingreso en 2016, bajo la medición de un examen diagnóstico, hasta el fin de ciclo 2017-2018. 


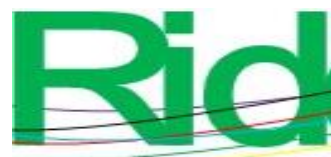

Revista Iberoamericana para la

Investigación y el Desarrollo Educativo ISSN $2007-7467$

Figura 10. Muestra de evolución de inglés por niveles, con cursos de inglés a contraturno. Informe final Inglés, Español e Historia. Julio de 2018

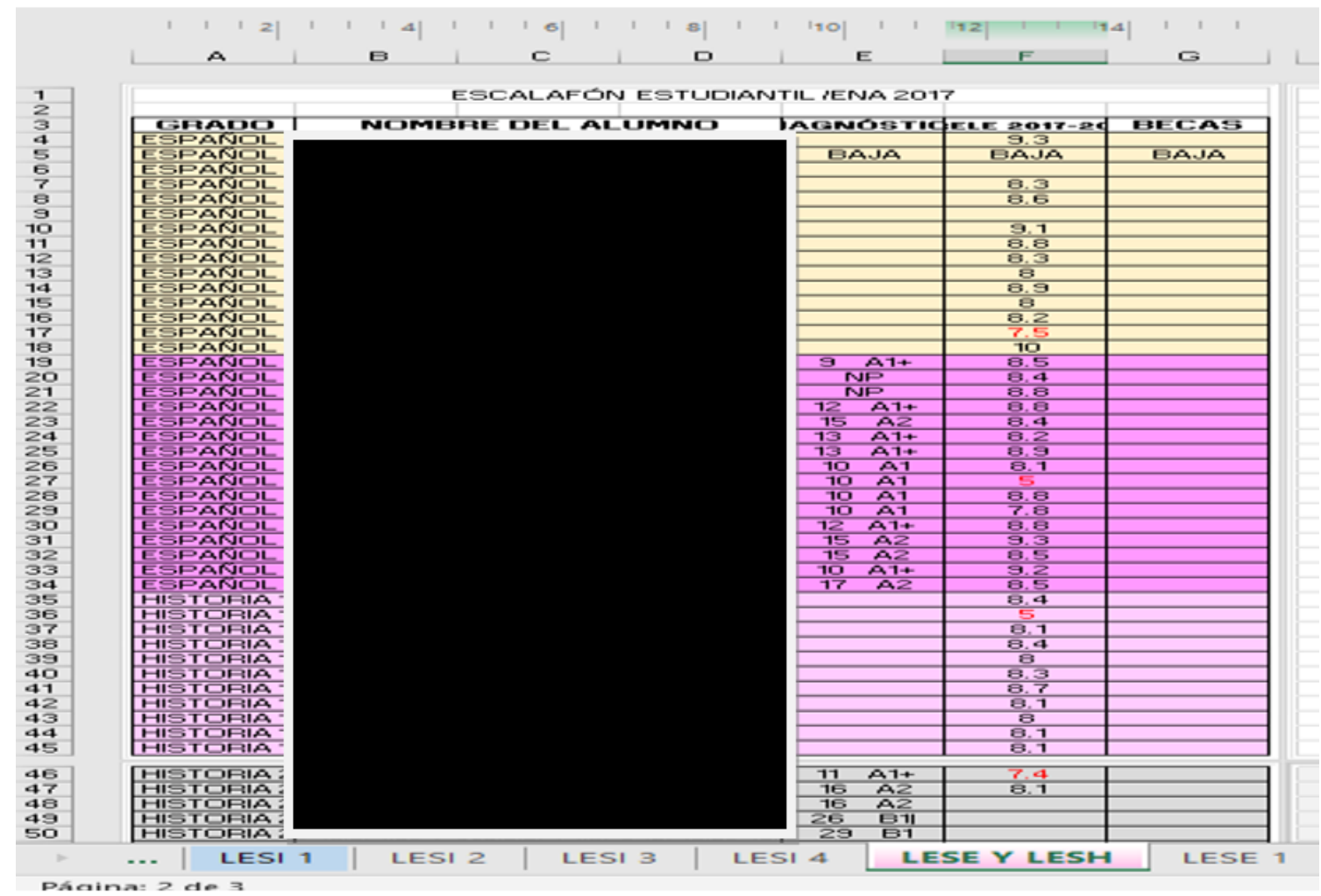

Fuente: Elaboración propia

Figura 11. Muestra de evolución de inglés por niveles, con cursos de inglés a contraturno. Informe final Inglés, Español e Historia. Julio de 2018

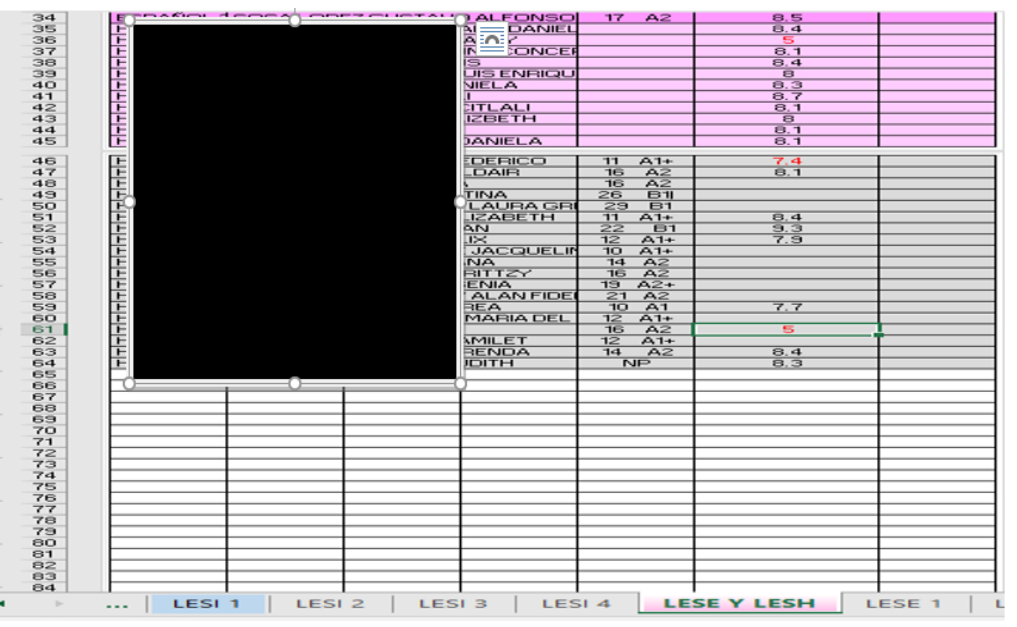

Fuente: Elaboración propia 




Revista Iberoamericana para la

Investigación y el Desarrollo Educativo

ISSN $2007-7467$

Derivado de la muestra generacional mostrada, podemos concluir que la plataforma de Wordpress es efectiva, y logra nivelar a los alumnos en el tiempo y nivel mencionados en el presente proyecto. Es de hacer notar que no ha sido una actividad aislada, sino dentro de una serie de cursos, talleres y plataformas, todo ello descrito en esta investigación. Así, pues, se prueba que, si bien la meta no se atribuye exclusivamente a la suite en Wordpress, sí al menos constituye un factor elemental para lograr el nivel deseado del alumnado al culminar la licenciatura.

\section{Discusión}

Como una propuesta en camino, se ha planteado la reformulación de cursos para docentes en formación, toda vez que, si bien su formación es plausible, se queda en el honor que lleva su nombre, solo y escasamente de formación inicial, donde se les prepara, en términos del plan de estudios 1999, para la ejecución de planes y programas, no para su adecuación y manejo de programas desde una flexibilidad curricular planteada desde el Acuerdo 650 (SEP, Diario Oficial de la Federación, 20 de agosto de 2012, p. 34) para su implementación, entre los que figuran cursos complementarios, asesoría y tutoría como acompañamiento académico; reconocimiento y acreditación de competencias, organización por trayectos formativos y posibilidades de movilidad nacional e internacional como un medio de diversificar las experiencias formativas, especialmente en el terreno lingüístico que nos ocupa.

Sin duda el Gobierno mexicano, en materia de educación, ha dado cuenta de la realidad planteada, y por ello ha puesto en marcha el nuevo modelo educativo 2018 en escuelas normales. Sin embargo, todavía no hay docentes suficientes con especialidad en inglés; tampoco hay entrega de materiales a tiempo para la ejecución de los cursos sugeridos (diseñados en colaboración con The British Council, a un precio accesible de 190.00 pesos por texto, acto muy plausible por parte del Gobierno mexicano), y el diseño de cursos en la plataforma de DGESPE aún en fase de diseño, cuando el plan de estudios ya estaba en marcha en agosto de 2018, como puede consultarse en la página de la propia DGESPE.

Debilidad manifiesta. No se duda en esta investigación del plan gubernamental descrito; lo que argumento es la temporalidad, condiciones y logística previa a la implementación de una reforma de tal magnitud, de modo preciso en materia de inglés. No 
bastaría con aumentar la carga horaria en educación superior, sin contar primero con una variedad de recursos de apoyo académico para el aprendizaje y la práctica del idioma en cuestión. En el caso concreto de la presente investigación, el diseño e implementación de una LMS en una suite gratuita, y en el presente, en una fase de conformación en una suite de licencia, Schoology, para lograr finalmente que el alumno acceda no solo en la institución (Intranet), sino en cualquier locación (Internet), y a través de una aplicación en sus celulares, insisto, ya en más de 50 \% de avance en su conformación. Será el tema de la continuación de esta investigación.

Nuestra meta específica en normales públicas es egresar a los mejores docentes, formados no solo en didáctica y pedagogía, sino también con un nivel suficiente (intermedio o B2) que les permita dignamente ejercer la docencia de cursos de inglés con los conocimientos que les aseguren lograr los objetivos planteados en el nivel que impartan sus sesiones.

\section{Conclusiones}

A manera de conclusión, se puede afirmar que, con personal capacitado y plataformas aún con software libre, y en modalidad de aplicación en celulares, es como podremos lograr los estándares que la reforma educativa plantea en términos de la adquisición del inglés como lengua extranjera en escuelas de pocos recursos. La propuesta es tácitamente extender la habilitación de todo estudiante normalista en el estudio de inglés como lengua extranjera, adyacente a sus cursos curriculares, con plataformas y talleres gratuitos de uso y dominio con enfoque comunicativo, en horario institucional y con trabajo autónomo.

Quienes estamos en esta parte de la historia del país por vocación, con gusto por lo que hacemos, y aún más por área de especialidad, tenemos clara la meta de forjar en los estudiantes la adquisición de una segunda lengua, el inglés, dentro de los parámetros sugeridos por el propio Gobierno federal a través de las instancias correspondientes. Trabajemos no solo juntos, sino unidos. La meta es clara. Los medios hoy también. La finalidad es clara. Hoy, expongo como alternativa una LMS sin costo, alojada en una suite interna, que toda escuela normal con un centro de cómputo podría obtener. Y el mismo diseño en una aplicación para celulares, en manos del alumnado a corto plazo. El tiempo ha llegado, y las metas están presentes. Así es como las abordo en mi contexto. 

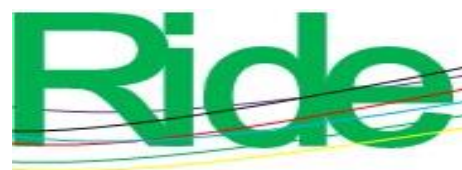

\section{Revista Iberoamericana para la Investigación y el Desarrollo Educativo ISSN $2007-7467$}

Para culminar con este artículo, cabe mencionar la intención de la proyección del diseño curricular a mi cargo, como continuidad de los procesos aquí expuestos a nivel licenciatura: El diseño curricular de la Maestría en Pedagogía del Inglés (MPI). Si bien las líneas trazadas son muy claras, desde cursos propedéuticos, evaluaciones diagnósticas y de ubicación; cursos de inglés por niveles, cursos de reforzamiento a contraturno; cursos remediales, si es necesario; puesta en marcha de dos plataformas de inglés de Cambridge University, y la propia creación de la LMS interna de tutoría especializada en inglés, para alumnos de todas las especialidades, y proyectada a existir en más escuelas normales, bajo la gestión correspondiente.

Pues no es todo. A la fecha, el sistema educativo mexicano ha tenido una limitante notable en el centro del país, y es la falta de oferta educativa después de la Licenciatura en Inglés, ofrecida en sus normales públicas. Veracruz y Yucatán son estados que cuentan con una maestría afín al perfil en mención; sin embargo, el Estado de México se ha de conformar, con o sin becas, a cursar maestrías en la Universidad Autónoma del Estado de México (UAEM) o en la Universidad de Southampton. No se escucha algo más. En el tintero, la propuesta es establecer una especialidad con cursos de metodología de la enseñanza del Teaching Knowledge Test (TKT) para alumnos normalistas de $4 .^{\circ}$ grado, con especialidad en inglés, pero, sobre todo, diseñar de modo formal y curricular la Maestría en Pedagogía del Inglés, no puesta en marcha desde el año 2010, cuando la DGESPE conoció el programa de estudios en ese momento. 


\section{Referencias}

British Council. (s. f.). Con quiénes trabajamos. British Council. Recuperado de http://www.britishcouncil.org.mx/asociaciones/nuestros-socios

Council for Cultural Cooperation. (2001). Common European Framework for Languages:

Learning, Teaching, Assessment. Strasbourg: Language policy division.

Dirección General de Educación Superior para Profesionales de la Educación [Dgespe]. (s.

f.). Directorio Completo de las Escuelas Normales de la República Mexicana. México: Dirección General de Educación Superior para Profesionales de la Educación. Recuperado de http://www.dgespe.sep.gob.mx/rs/ens/directorio/escuelas

Doff, A., Thaine, C., Putcha, H., Stranks, J. and Lewis-Jones P. (2018). Empower. United Kingdom: Cambridge University Press.

LIENI (2014). Plataforma construida: English Lab at Escuela Normal de Ixtlahuaca. México: Autor.

Real Academia Española [RAE]. (2014) Diccionario de la Lengua Española (22. ${ }^{\text {a ed.). }}$ Madrid, España: Real Academia Española.

Richards, J., Hull, J. and Proctor, S. (2018). New Interchange (5 ${ }^{\text {th }}$ ed.). United Kingdom: Cambridge University Press.

Schoology. (2015). B1 ENI course. Retrieved from https://app.schoology.com/course/414145819/materials?f=28886869

Secretaría de Educación Pública [SEP]. (2008) Alianza por la calidad de la educación. México: Secretaría de Educación Pública.

Secretaría de Educación Pública [SEP]. (2010) Programa Nacional de Inglés para Educación Básica. México: Secretaría de Educación Pública. Recuperado de http://www.pnieb.net/inicio.html

Secretaría de Educación Pública [SEP]. (20 de agosto de 2012) Acuerdo 650. Diario Oficial de la Federación.

Secretaría de Educación Pública [SEP]. (s. f). Plan de Estudios 2012. México: DGESPE. Secretaría de Educación Pública [SEP]. (s. f). Plan de Estudios 2018. México: DGESPE. Recuperado de https://www.cevie-dgespe.com/index.php/planes-de-estudios$2018 / 74$. 